\title{
Avaliação do efeito térmico das intrusivas ígneas em um horizonte potencialmente gerador da Bacia do Paraná: Formação Irati
}

\author{
Igor Viegas Alves Fernandes de Souza ${ }^{1}$, Joũo Graciano Mendonça Filho ${ }^{2}$ \\ \& Taíssa Rêgo Menezes ${ }^{I}$
}

\begin{abstract}
Resumo O objetivo deste trabalho foi determinar a quantidade, qualidade e grau de evolução térmica da matéria orgânica presente em seções da Formação Irati afetadas termicamente por corpos ígneos. As análises de petrografia orgânica associadas aos dados de carbono orgânico total e pirólise Rock-Eval revelaram uma qualidade e quantidade adequada de matéria orgânica para geração de petróleo. Os resultados de biomarcadores indicaram um baixo grau de evolução térmica para os extratos situados dentro da zona de gás úmido/gás seco, sugerindo a presença de hidrocarbonetos migrados. Estes resultados evidenciam que a espessura da seção afetada pelo efeito térmico de intrusivas ígneas depende da temperatura de intrusão do corpo ígneo, profundidade em que ocorreu a intrusão e condutividade térmica da encaixante, que explicaria as diferenças observadas no perfil de maturação.
\end{abstract}

Palavras-chave: Formação Irati, Intrusões ígneas, Geoquímica Orgânica, Petrografia Orgânica.

\begin{abstract}
Thermal effect appraisal of the igneous intrusions on a potential source rock from Paraná basin: Iratiformation. The objective of this work was to determine the amount, type and thermal evolution of organic matter in sections of Irati Formation thermally affected by igneous intrusions. Organic petrographic analyse, Total Organic Carbon and Rock-Eval pyrolysis data showed a suitable amount and type of organic matter for oil generation. The biomarker data indicated a low degree of thermal evolution for the extract sampled in the wet gas/dry gas zone, suggesting the presence of migrated hydrocarbons. It was noted that the thickness of the section affected by igneous intrusions depends on the temperature of the igneous body, depth of intrusion and thermal conductivity, which could explain the differences between maturation logs.
\end{abstract}

Keywords: Irati Formation, Igneous intrusion, Organic Geochemical, Organic Petrography.

INTRODUÇÃO A Bacia do Paraná apresenta diversos indícios de petróleo em superfície e subsuperfície e os resultados exploratórios mais significativos foram alcançados com produções subcomerciais de hidrocarbonetos líquidos e gasosos em diversos horizontes estratigráficos, ressaltando a multiplicidade de situações exploratórias (Milani et al., 1990). Dados de análises geoquímicas indicam que a Formação Irati é a mais propícia a apresentar rochas geradoras de petróleo na Bacia do Paraná, além de possuir correlação geoquímica com grande parte das ocorrências de óleo e gás. Esta formação é constituída por rochas ricas em matéria orgânica potencialmente geradora de óleo e encontra-se imatura em grande parte da bacia. Entretanto, em alguns locais da bacia a Formação Irati apresenta-se em contato com rochas intrusivas de idade mesozóica, propiciando um processo de maturação atípico (Mendonça Filho, 1994; Araújo et al. 2000). Segundo Corrêa \& Pereira (2005), as idades radiométricas baseadas em K-Ar e Ar-Ar deste magmatismo variam entre 133 e $123 \mathrm{Ma}$, com indicação de idades mais jovens para SE. Estes mesmos autores propuseram novos modelos não-convencionais de geração de óleo e gás para a Bacia do Paraná.
O objetivo principal deste trabalho é analisar o comportamento dos parâmetros organopetrográficos (índice de coloração de esporos - ICE, poder refletor da vitrinita e composição orgânica) e organogeoquímicos (Carbono Orgânico Total - COT, pirólise Rock-Eval e biomarcadores) em zonas afetadas termicamente por corpos ígneos, fornecendo dados sobre qualidade, quantidade e estágio de evolução térmica da matéria orgânica para determinação do potencial de geração e caracterização do processo de geração de hidrocarbonetos. Para tanto, foram analisadas 104 amostras de três regiões da Bacia do Paraná (Paraná, Rio Grande do Sul e Goiás). A Formação Irati ainda carece de estudos mais conclusivos no que se refere ao estágio de evolução térmica da matéria orgânica e o conhecimento sobre o processo de geração de petróleo por influência térmica de intrusivas ígneas precisa ser mais profundamente estudado. Esta carência de estudos se mostra mais contundente na porção setentrional da Bacia do Paraná .

CONTEXTO GEOLÓGiCO A Bacia do Paraná é uma extensa bacia intracratônica $\left(1.100 .000 \mathrm{~km}^{2}\right)$, que abrange parte dos estados do Mato Grosso, Goi- 
ás, Minas Gerais, Mato Grosso do Sul, São Paulo, Paraná, Santa Catarina e Rio Grande do Sul. A gênese desta bacia está relacionada à estabilização geológica da Plataforma Sul-Americana após o estágio final do Ciclo Orogênico Brasiliano (Proterozóico superior/Paleozóico inferior). Está bacia apresenta uma espessura em torno de $5.000 \mathrm{~m}$ no seu depocentro e é constituída por rochas sedimentares e ígneas. Segundo Milani et al. (1994) e Milani \& Zalán (1999), a Bacia do Paraná apresenta seis superseqüências, datadas do Ordoviciano ao Cretáceo: Seqüências Rio Ivaí (Grupo Rio Ivaí, Ordoviciano-Siluriano), Paraná (Grupo Paraná, Devoniano), Gondwana I (Grupos Tubarão e Passa Dois, Carbonífero-Permiano), Gondwana II (unidades Triássicas), Gondwana III (Grupo São Bento, JurássicoCretáceo) e Bauru (Cretáceo).

White (1908) utilizou o termo Irati para designar a seqüência de folhelhos com restos do réptil Mesosaurus brasiliensis, que aflora na cidade homônima no Estado do Paraná. Esta formação pertencente à porção basal do Grupo Passa Dois encontra-se estratigraficamente sobreposta à Formação Palermo (Grupo Guatá) e sotoposta à Formação Serra Alta, apresentado contato concordante, com exceção feita à área de São Paulo, onde são descritas relações discordantes (Schneider et. al., 1974). Muitas interpretações, subdivisões e variadas denominações têm sido atribuídas nas regiões onde ocorre a Formação Irati. A estratigrafia desta formação, desde que foi proposta por White (1908), tem sofrido várias modificações. A bibliografia sobre tal formação foi sumarizada e discutida por Mendes (1967) e Bigarella (1972). No presente trabalho foi utilizada a carta estratigráfica da Bacia do Paraná proposta por Milani et al. (1994). A Formação Irati é caracterizada por uma faciologia bastante complexa, constituída por folhelho, folhelho betuminoso, arenito, marga, carbonato e anidrita, indicativo de uma geometria de bacia igualmente complexa, em que se confinavam golfos e baías de profundidades e salinidades bastante variáveis (Daemon et al., 1991 apud Milani et al., 1994). A seqüência de folhelhos e siltitos da base da formação constitui o Membro Taquaral. Já o Membro Assistência é caracterizado por uma seção de folhelhos cinza escuro a pretos pirobetuminosos e calcários. O Membro Taquaral, segundo Schneider et al. (1974), possui características litológicas e sedimentares que indicam deposição em ambiente marinho de águas calmas, abaixo do nível de ações de ondas. Já o Membro Assistência possui características litológicas e sedimentares que sugerem deposição em ambiente marinho de águas rasas, apresentando restrições que criaram condições de baixa oxigenação para a deposição de folhelhos pirobetuminosos associados a calcários.

Daemon \& Quadros (1970) através de estudos palinológicos indicam a idade Permiano Superior (Kazaniano) para a Formação Irati (267 Ma). Santos et al. (2006) atribuíram à Formação Irati a idade Artinskiano (278,4 \pm 2,2), através da datação de camadas de bentonita dentro da Formação Irati, utilizando o método Shirimp U-Pb.

MATERIAL DE ESTUDO As amostras utilizadas neste trabalho são de testemunho e de afloramento e foram coletadas em dois poços, localizados nos estados do Rio Grande do Sul e Paraná, e em afloramentos no Estado de Goiás (Fig. 1). A amostragem buscou a melhor representação das seções analisadas.

As amostras do poço RN 16/96 foram cedidas pelo Núcleo de Exploração da Bacia do Paraná NEXPAR-PETROBRAS (Projeto SIX), localizado a sudeste do Estado do Paraná (Rio Negro). Já as amostras do poço 5-CA-73-RS-19, foram cedidas pela Companhia de Pesquisa de Recursos Minerais (CPRM), perfurado no âmbito dos projetos Carvão no Rio Grande do Sul, fronteira oeste Bagé-São Gabriel e Grande Candiota, que se encontram sumarizados no Projeto Borda Leste (DNPM/CPRM), localizado no Município Cachoeira do Sul, Rio Grande do Sul. As amostras coletadas do perfil estratigráfico, localizado no Município de Perolândia (na Pedreira SUCAL), no estado de Goiás, foram obtidas através do Projeto CNPq/CTPETRO 2001/2002 - UnB/UFRJ intitulado "Estudo da influência térmica das intrusões ígneas no principal horizonte potencialmente gerador da porção setentrional na bacia do Paraná: Formação Irati”.

MÉTODOS DE TRABALHO Os teores de carbono orgânico total (COT) foram determinados por combustão no analisador de carbono LECO. Posteriormente, foi realizada a pirólise no equipamento Rock-Eval 6 Turbo para a determinação da presença de hidrocarbonetos livres $\left(\mathrm{S}_{1}\right)$, potencial gerador $\left(\mathrm{S}_{2}\right)$, índices de hidrogênio (IH) e temperatura máxima da pirólise (Tmáx).

Para a extração do betume foi utilizado o sis-

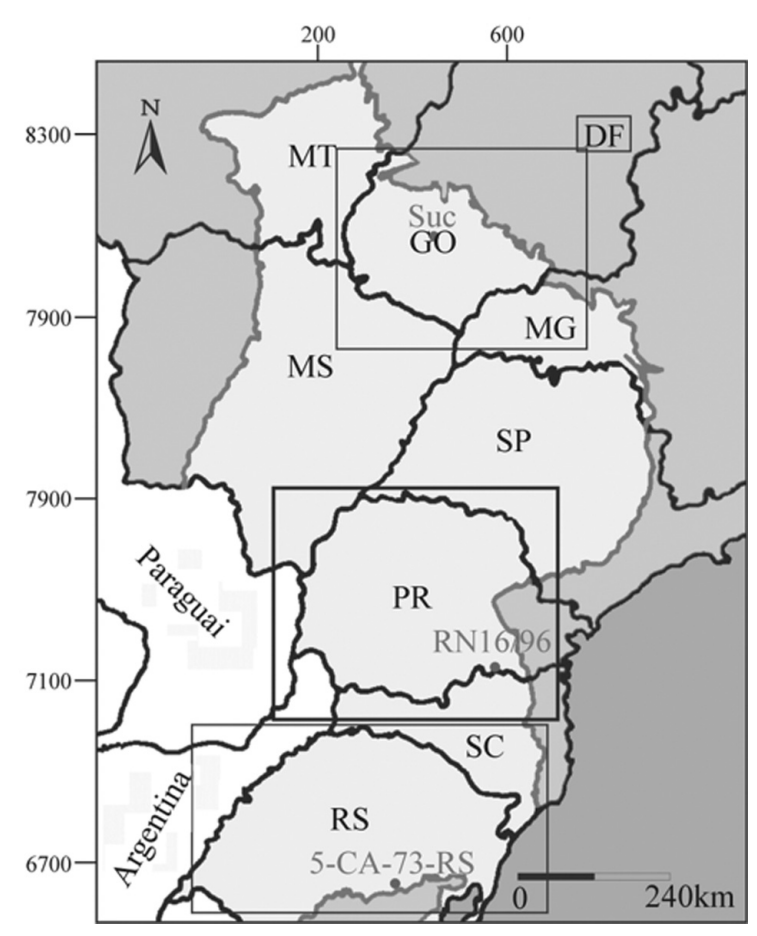

Figura 1 - Mapa de localização dos poços RN16/96 e 5-CA-73-RS-19 e do afloramento da pedreira SUCAL. 
tema sohxlet (com adição de diclorometano), e para a análise de cromatografia líquida foi utilizado um sistema MPLC. A fração de hidrocarbonetos alifáticos foi analisada por um cromatógrafo gasoso acoplado a um espectrômetro de massa (CG-EM).

A preparação de amostras para obtenção do querogênio isolado para as análises de maturação e composição orgânica seguiu os procedimentos descritos por Mendonça Filho (1994). As amostras foram tratadas com ácido clorídrico e fluorídrico para eliminação da matriz mineral. Posteriormente foi realizada a etapa de separação do querogênio do resíduo mineral com utilização de cloreto de zinco. Após o processo de isolamento da matéria orgânica foram confeccionadas lâminas e seções polidas de concentrado de querogênio para as análises em luz branca transmitida, refletida e azul incidente. A composição orgânica foi determinada através da estimativa visual dos três grandes grupos da matéria orgânica (Matéria Orgânica Amorfa, Lenhosa e liptinítica. A luz azul incidente foi utilizada com o intuito de avaliar a coloração da fluorescência. Segundo (Tyson, 1995), a fluorescência é produzida por processos fotoquímicos. A alta energia UV / luz de curto comprimento de onda (azul) excita os elétrons atingidos, fazendo com que se elevem para um orbital de maior energia. Quando esses elétrons retornam a sua posição original, energia sob a forma de fótons é liberada como energia mais baixa/luz visível de comprimento de onda mais longo (usualmente verde-amarelo com filtros comuns). Este processo fotoquímico é produzido por componentes cromóforos ou fluoróforos específicos, e não pela matéria orgânica em geral.

\section{RESULTADOS}

Maturação Térmica $\mathrm{O}$ grau de evolução térmica das amostras foi obtido pelo índice de coloração de esporos (ICE) e poder refletor da vitrinita (\%Ro). O ICE foi aplicado em esporos e grãos de pólen. Para cada amostra procurou-se determinar a cor de maior número de indivíduos possível, estabelecendo de um modo geral, como índice da amostra, a cor predominante. Foi utilizado o padrão de ICE da Robertson Research International Group (Barnard et al., 1981). Os resultados de Ro representam as medidas da reflectância em vitrinitas, realizadas em plugs de concentrado de querogênio.

Barnard et al. (1981) construíram um gráfico que correlaciona os valores dos parâmetros óticos de maturação (ICE e \%Ro) para razões de aquecimento constante. Segundo este autores, a janela de geração de óleo, no Neo-Permiano, ocorre com valores de ICE entre 5,0 e 9,0, no processo natural de aumento de temperatura, em conseqüência do aumento da profundidade de soterramento.

O ICE das amostras do poço RN 16/96 apresenta uma grande variação, desde 3,0 até 10,0 (Fig. 2). Já os resultados de Ro (\%) apresentaram valores variando entre $0,44 \%$ a $1,29 \%$, indicando um alto grau de evolução térmica próximo a intrusiva (Fig. 2).

Os resultados de ICE e Ro (\%) das amostras do poço 5-CA-73-RS-19 variam de 9,0 a 9,5 e 1,3 a 1,5, respectivamente (Fig. 3). Tais resultados indicam que as amostras analisadas apresentam um alto grau de evolução térmica (zona de gás úmido). As amostras do afloramento da pedreira SUCAL apresentam um ICE que varia de 4,0 a 10,0, sendo que os maiores valores estão relacionados a proximidade da intrusiva ígnea (Fig. 4).

COT e Pirólise Rock-Eval Os teores de COT e os resultados da análise de pirólise das amostras do testemunho RN 16/96 estão sumarizados na figura 2. No geral, os teores de COT são moderados a altos, apresentado teores de até $17,3 \%$, com exceção de três amostras coletadas na base do testemunho, que apresentam teores inferiores a $1 \%$. Os teores de COT estão associados à fácies orgânica, grau de evolução térmica e presença

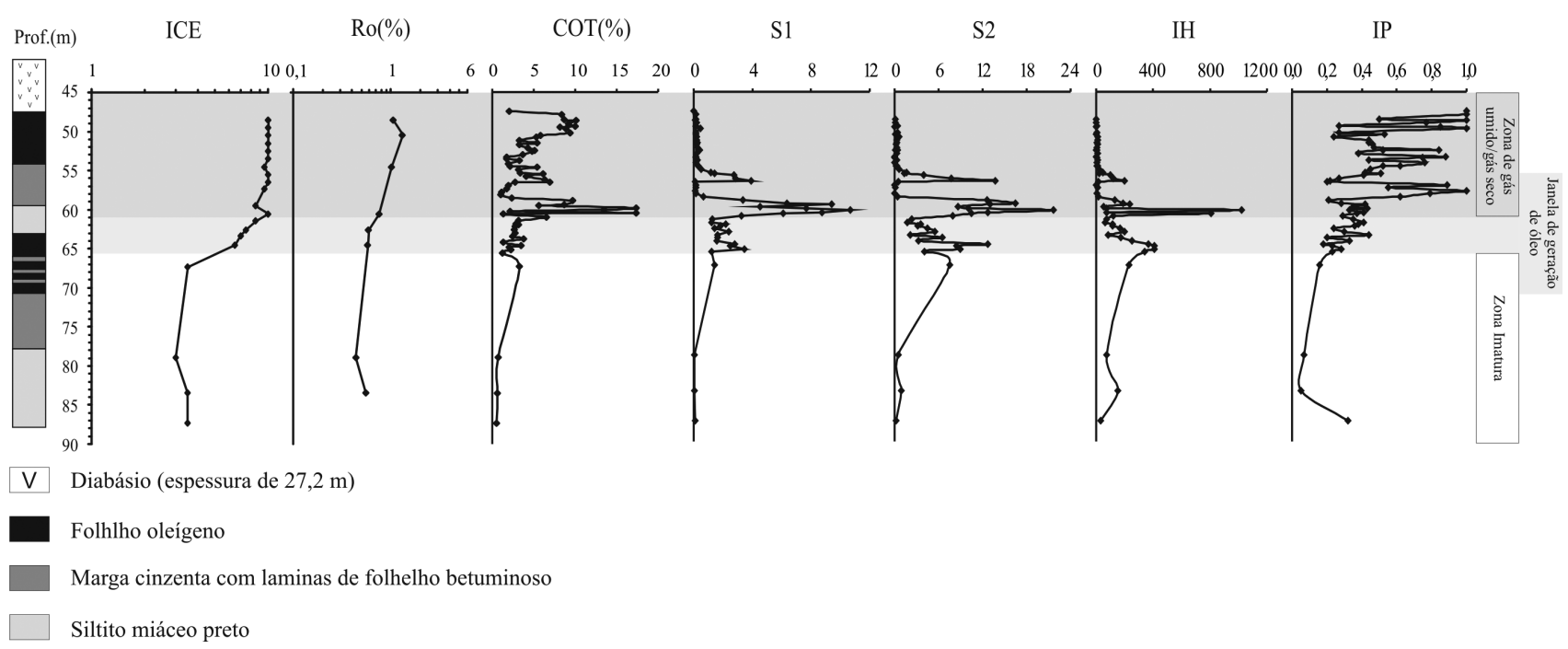

Figura 2 - Correlação entre os parâmetros fisicos de maturação e os parâmetros geoquímicos das amostras do poço RN 16/96. 


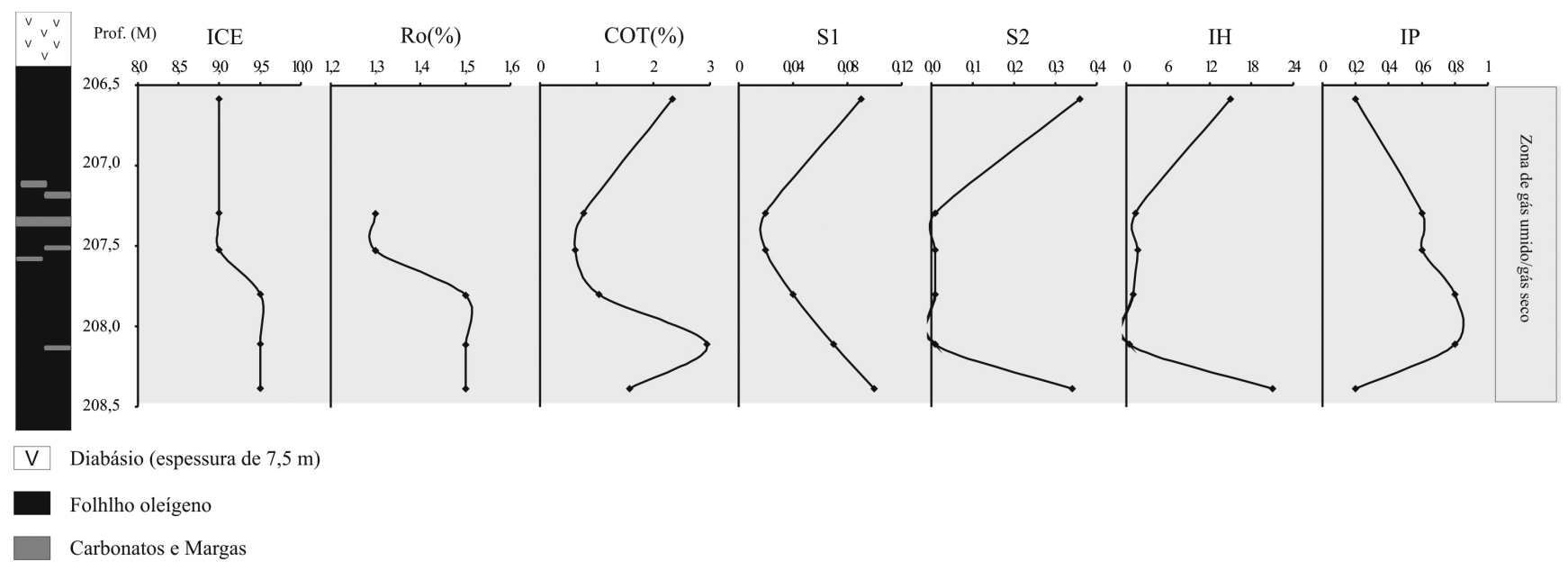

Figura 3 - Correlação entre os parâmetros físicos de maturação e os parâmetros geoquímicos das amostras do poço 5-CA-73-RS-19.

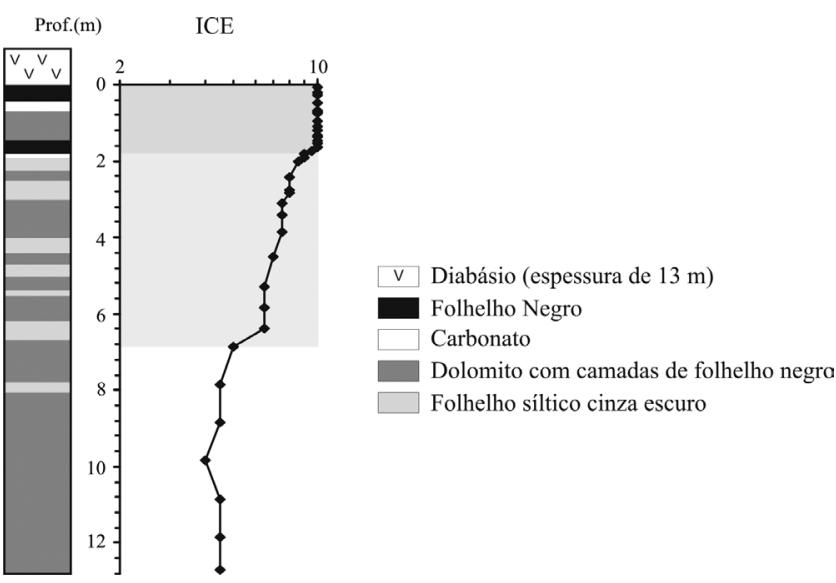

Figura 4 - Perfil de Evolução térmica do afloramento da pedreira SUCAL.

de hidrocarbonetos. Os valores de $\mathrm{S}_{1}$ variam de $0,02 \mathrm{a}$ $10,69 \mathrm{mg} \mathrm{HC} / \mathrm{g}$ rocha. Os resultados mais elevados de $\mathrm{S}_{1}$ são bons indicadores da ocorrência do processo de geração. Os valores de $\mathrm{S}_{2}$ são baixos a elevados, variando entre 0,02 a $21,67 \mathrm{mg} \mathrm{HC} / \mathrm{g}$ rocha e estão relacionados à qualidade das fácies geradoras e grau de evolução térmica. É importante ressaltar que os valores de $\mathrm{S}_{2}$ podem estar influenciados pelos altos valores de $\mathrm{S}_{1}$. Outro fator relevante, é que os resultados $\mathrm{S}_{2}$ inferiores a $2 \mathrm{mg} \mathrm{HC/g}$ rocha não são confiáveis, pois estão abaixo do limite de detecção do equipamento. Os valores de índice de hidrogênio (IH) variam de 0 a 1022 mg HC/g COT e estão relacionados ao tipo de querogênio, presença de hidrocarbonetos e ao grau de evolução térmica da matéria orgânica. Os valores de IH das amostras que apresentam um baixo grau de evolução térmica indicam um predomínio do querogênio tipo I/II e II no poço RN 16/96. Os valores de Tmax são inferiores a $440^{\circ} \mathrm{C}$, indicando um baixo grau de evolução térmica.
Entretanto, os valores de Tmáx das amostras afetadas termicamente pela intrusiva ígnea não são confiáveis, devido os baixos valores de $\mathrm{S}_{2}$. Os valores do índice de produção variam entre $0,05 \mathrm{e} 1$, onde a maioria dos valores são superiores a 0,2 , indicando um alto grau de evolução térmica.

Os teores de COT e os resultados de pirólise do testemunho 5-CA-73-RS-19 estão expressos na figura 3. Os teores de COT são baixos a moderados, variando de 0,62 a 2,95\%. Estes resultados de COT estão relacionados à fácies orgânica e o alto grau de evolução térmica. Os valores de $\mathrm{S}_{1}$ e $\mathrm{S}$, são baixos, inferiores a 0,2 e $1 \mathrm{mg} \mathrm{HC} / \mathrm{g}$ rocha, respectivamente. Os valores de IH são muito baixos, estando diretamente relacionado ao alto grau de evolução térmica, não sendo possível avaliar o tipo de querogênio presente nas amostras. Os valores de Tmáx não são confiáveis, pois os valores de $\mathrm{S}_{2}$ são inferiores a $2 \mathrm{mg} \mathrm{HC} / \mathrm{g}$ rocha. Os valores de IP indicam um alto grau de evolução térmica para toda seção (valores superiores a 0,2 ).

Composição Orgânica Os resultados da composição orgânica das amostras coletadas nos testemunho RN 16/96 e 5-CA-73-RS-19 e no afloramento localizado na pedreira SUCAL estão expressos em diagramas ternários (Fig. 5). De maneira geral, as amostras coletadas no testemunho RN 16/96 apresentaram um predomínio de matéria orgânica amorfa em relação à matéria orgânica lenhosa e ao material liptinítico. Entretanto, o intervalo entre as profundidades de 62 e $87,3 \mathrm{~m}$ apresentou um predomínio da matéria orgânica lenhosa, com exceção das amostras coletadas nas profundidades de 63,4 e 67,3 $\mathrm{m}$, que apresentaram um predomínio de matéria orgânica amorfa e material liptinítico, respectivamente.

As amostras coletadas no testemunho 5-CA-73 -RS-19 apresentam um predomínio de matéria orgânica amorfa em relação à matéria orgânica lenhosa e a liptinítica, com exceção da amostra coletada na profundidade de 208,39 m, que apresenta um predomínio de 

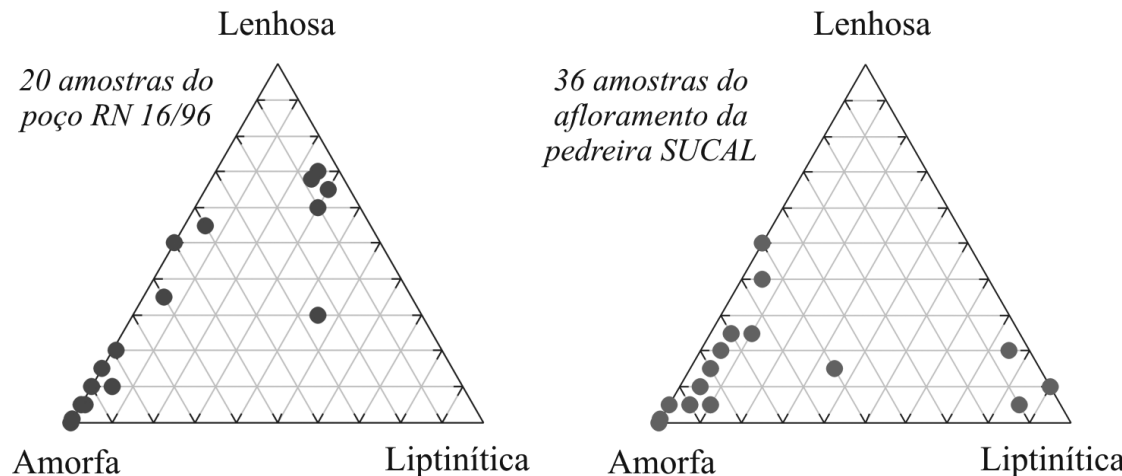

Amorfa

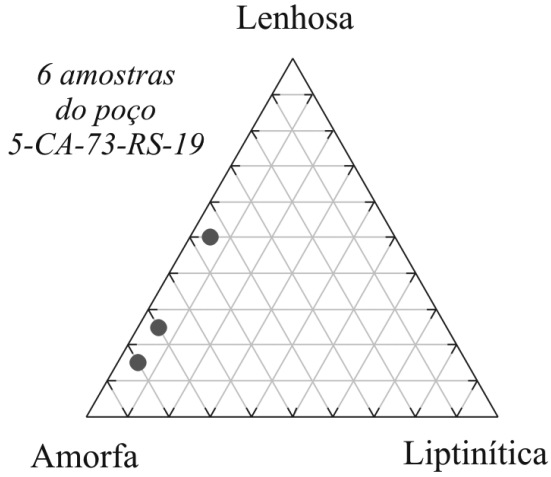

Figura 5 - Diagramas Ternários ilustrando a composição orgânica.

material lenhoso.

De maneira geral, as amostras coletadas no afloramento da pedreira SUCAL apresentaram um predomínio da matéria orgânica amorfa em relação à matéria orgânica lenhosa e ao material liptinítica. com exceção das amostras coletadas nas profundidades $6,85,8,85$ e 12,7 $\mathrm{m}$ apresentaram um predomínio de material liptinítica.

Em todas as lâminas analisadas foi observada matéria orgânica amorfa em forma de grumos, por vezes, muito densos, com coloração variando do amarelo claro a preto. A coloração da fluorescência da matéria orgânica amorfa das amostras não alteradas termicamente varia de laranja claro a laranja escuro. Já a matéria orgânica amorfa das amostras que estão termicamente alteradas apresenta coloração de fluorescência laranja escuro ou ausente.

A matéria orgânica liptinítica está representada por esporomorfos (esporos e grãos de pólen mono e bissacados), por vezes muito degradada e algas do gênero Botryococcus. Foi observada a presença de palinomorfos marinhos (acritarcos) na base do testemunho RN 16/96 (Mb. Taquaral) e cutículas no testemunho 5-CA-73-RS-19. A coloração de fluorescência dos esporomorfos das amostras não alteradas termicamente varia de amarelo claro a laranja escuro e a coloração da fluorescência das algas é amarelo intenso. Já os esporomorfos e algas das amostras termicamente afetadas pelas intrusivas ígneas apresentam coloração de fluorescência laranja ou ausência de fluorescência.

A matéria orgânica lenhosa está representada por fragmentos irregulares, com contornos bem nítidos angulares a subangulares e apresenta, em alguns casos, estruturação interna.

Cabe ressaltar que foi observada a presença de betume em quase todas as lâminas analisadas, podendo ser associado ao tipo de fácies orgânica (oil prone) ou craqueamento térmico da matéria orgânica pela influência térmica da intrusiva.

A variação da composição da matéria orgânica (palinofácies sensu Tyson, 1995), principalmente observada no testemunho RN 16/96 e no afloramento da pedreira SUCAL, está relacionada à mudança nas condições paleoambientais. A coloração de fluorescên- cia dos componentes orgânicos é controlada por fatores paleoambientais e pela maturidade térmica, onde as colorações mais escuras ou a ausência de fluorescência estão relacionadas a condições paleoambientais mais oxidantes ou evolução térmica mais elevada.

No geral, as amostras analisadas apresentam excelente qualidade de matéria orgânica para geração de petróleo, com predomínio do querogênio Tipo II/I e II. Na figura 4, as amostras apresentam o predomínio de matéria orgânica amorfa com coloração de fluorescência amarela a laranja clara. Em menores proporções ocorrem esporomorfos com coloração de fluorescência amarelo claro ao amarelo alaranjado e matéria orgânica lenhosa. As amostras afetadas termicamente por intrusivas ígneas apresentam modificações na coloração de fluorescência que se apresenta marrom escuro ou sem fluorescência devido ao efeito térmico.

Cromatografia Líquida A cromatografia líquida foi realizada a partir da extração do betume contido nas amostras, tendo como resultado a separação das frações de hidrocarbonetos alifáticos (parafinas), hidrocarbonetos aromáticos e compostos NSO. De acordo com Tissot \& Welte (1984), a razão da concentração entre hidrocarbonetos saturados e aromáticos pode indicar o estágio de evolução térmica dos sedimentos, ocorrendo o aumento dessa razão com o incremento da maturação. Porém, Trigüis (1986) e Mendonça Filho (1994) atentam para a possibilidade de não existir uma correlação entre os resultados de maturidade térmica obtidos pelos parâmetros óticos e a razão entre hidrocarbonetos saturados e aromáticos nas amostras da Formação Irati, mostrando que as amostras imaturas exibiam altos valores para esta razão. Estes mesmos autores acrescentam, ainda, a possibilidade de esses resultados estarem melhor relacionados à riqueza orgânica das amostras do que a evolução térmica. $\mathrm{O}$ diagrama ternário que relaciona as porcentagens de hidrocarbonetos saturados, hidrocarbonetos aromáticos e compostos NSO foi proposto por Tissot \& Welte (1984), os quais utilizariam tais diagramas como indicativo da composição total de óleos brutos. Posteriormente, Rohrback (1983) viria sugerir este diagrama como um indicador de maturidade. 
Os resultados de fracionamento do extrato orgânico das amostras do poço RN 16/96 estão representados na tabela 1 . As razões de hidrocarbonetos saturados para hidrocarbonetos aromáticos variam de 1,13 a 4,75, evidenciando o alto grau de evolução térmica que as amostras sofreram. É possível observar que a maioria das amostras apresenta proporções similares de saturados, aromáticos e compostos NSO, que evidenciam um estágio de evolução térmica semelhante, com exceção da amostra coletada na profundidade de $55,5 \mathrm{~m}$, pois se encontra num estágio mais desenvolvido de evolução térmica (Fig. 6).

Os resultados da cromatografia líquida das amostras do poço 5-CA-73-RS-19 estão representados na tabela 1. As razões de hidrocarbonetos saturados para hidrocarbonetos aromáticos variam de 2,24 a 5,99, com exceção das amostras que apresentaram 100\% de parafinas (amostras coletadas nas profundidades de 207,3 e 208,11 m), evidenciando o alto grau de maturação térmica dessas amostras. De acordo com o diagrama mostrado na figura 6, as amostras estão espalhadas por uma grande área e apresentam um trend de maturação, onde as amostras coletadas nas profundidades de 207,3 e 208,11 m se encontram no estágio mais avançado de evolução térmica.

Biomarcadores Segundo Seifert \& Moldowan (1980), a proporção da razão $22 \mathrm{~S} / 22 \mathrm{~S}+22 \mathrm{R}$ eleva-se a $60 \%$ (valor aproximado do equilíbrio) com o aumento do grau de evolução térmica, alcançando esta porcentagem antes do pico de geração de óleo. As medidas de isomerização dessas amostras foram realizadas no hopano $\mathrm{C}_{32}$. De acordo com Mackenzie (1984) a medida de isomerização nos hopanos $\mathrm{C}_{32}$ apresenta resultados mais confiáveis, uma vez que os homólogos superiores geralmente estão presentes em baixas concentra-

Tabela 1 - Resultados de extração, cromatografia líquida e das razões de isomerização dos biomarcadores das amostras dos poços 16/96 e 5-CA-73-RS-19.

\begin{tabular}{|c|c|c|c|c|c|c|c|c|c|}
\hline Poço & Prof.(m) & Ext.(ppm) & Sat. (\%) & Arom. $(\%)$ & $\begin{array}{l}\text { Comp. } \\
\text { NOS (\%) }\end{array}$ & $\begin{array}{l}\text { Sat./ } \\
\text { Arom. }\end{array}$ & $\begin{array}{c}\mathrm{C} 32 \\
(22 \mathrm{~S} / 22 \mathrm{~S}+22 \mathrm{R})\end{array}$ & $\begin{array}{c}\text { C30 (Hop/ } \\
\text { Hop+Moret) }\end{array}$ & $\mathrm{Tm} / \mathrm{Ts}$ \\
\hline \multirow{16}{*}{$\begin{array}{l}\circ \\
\stackrel{\circ}{6} \\
\stackrel{z}{z}\end{array}$} & 47,50 & 0,0 & & & & & & & \\
\hline & 48,50 & 0,0 & & & & & & & \\
\hline & 49,50 & 0,0 & & & & & & & \\
\hline & 50,50 & 0,0 & & & & & & & \\
\hline & 51,50 & 0,0 & & & & & & & \\
\hline & 52,50 & 0,0 & & & & & & & \\
\hline & 53,50 & 0,0 & & & & & & & \\
\hline & 54,50 & 0,0 & & & & & & & \\
\hline & 55,50 & 1918,0 & 66,43 & 13,99 & 19,58 & 4,75 & & & \\
\hline & 56,50 & 12839,7 & 39,51 & 23,66 & 36,83 & 1,67 & 0,59 & 0,85 & 3,26 \\
\hline & 59,50 & 24970,0 & 32,01 & 21,03 & 46,96 & 1,52 & 0,58 & 0,85 & 3,41 \\
\hline & 60,00 & 21965,6 & 32,97 & 23,8 & 43,23 & 1,39 & 0,58 & 0,86 & 3,58 \\
\hline & 60,50 & 22364,1 & 31,49 & 27,86 & 40,65 & 1,13 & 0,58 & 0,82 & 2,94 \\
\hline & 61,00 & 18908,3 & 33,75 & 25,16 & 41,09 & 1,34 & 0,58 & 0,86 & 3,97 \\
\hline & 62,00 & 7628,8 & 39,26 & 26,03 & 34,71 & 1,51 & 0,49 & 0,86 & 4,24 \\
\hline & 63,00 & 7980,2 & 34,82 & 19,23 & 45,95 & 1,81 & 0,58 & 0,85 & 3,61 \\
\hline \multirow{5}{*}{ 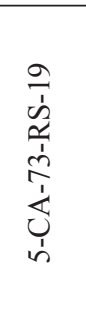 } & 207,30 & 231,0 & \multicolumn{4}{|c|}{ Parafinas } & 1,50 & 0,50 & 0,82 \\
\hline & 207,53 & 290,8 & 29,37 & 4,9 & 65,73 & 5,99 & 1,40 & 0,49 & 0,78 \\
\hline & 207,80 & 237,4 & 40,52 & 18,1 & 41,38 & 2,24 & 3,60 & 0,40 & 0,75 \\
\hline & 208,11 & 524,0 & \multicolumn{4}{|c|}{ Parafinas } & 3,80 & 0,36 & 0,70 \\
\hline & 208,39 & 364,7 & 40,2 & 7,04 & 52,76 & 5,71 & 2,60 & 0,33 & 0,73 \\
\hline
\end{tabular}



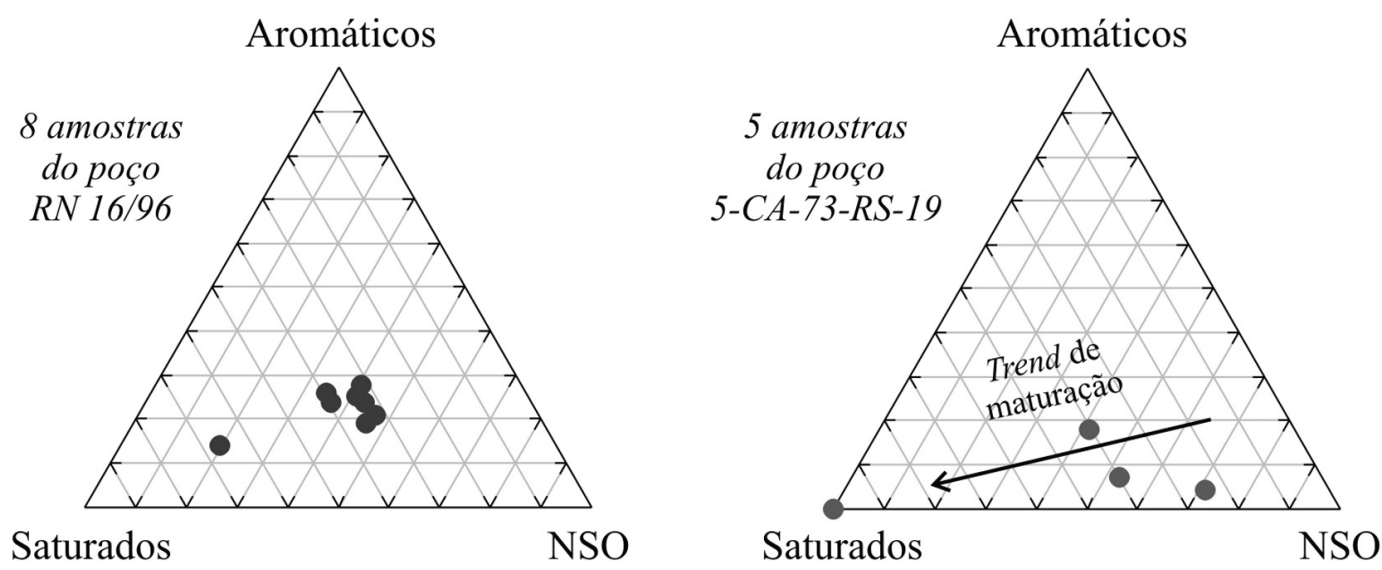

Figura 6 - Diagramas ternários mostrando a composição das frações de hidrocarbonetos das amostras dos poços RN 16/96 e 5-CA-73-RS-19.

ções relativas. No caso do $\mathrm{C}_{31}$, existe a possibilidade de coeluição do gamacerano com o $22 \mathrm{R} \mathrm{C}_{31}$ hopano, devendo sempre que possível ser evitado (Mackenzie et al., 1982). Os valores desta razão de isomerização para as amostras do testemunho RN 16/96 se encontram expressos na tabela 1 e variam de 0,49 a 0,59 , indicando um grau de evolução térmica entre o início da janela de geração de óleo e o pico de geração de óleo. Os valores desta razão de isomerização para as amostras do testemunho 5-CA-73-RS-19 se encontram expressos na tabela 1 e variam de 0,33 a 0,50 , indicando uma evolução térmica inferior às amostras do testemunho RN 16/96.

Em amostras de sedimentos mais imaturos, as estruturas dominantes são normalmente os $17 \beta(\mathrm{H})$, $21 \beta(\mathrm{H})$ hopanos, embora os componentes $17 \beta(\mathrm{H}), 21 \alpha$ $(\mathrm{H})$ e $17 \alpha(\mathrm{H}), 21 \beta(\mathrm{H})$ estejam presentes em quantidades relativas variáveis (Mackenzie et al., 1980). A estabilidade dos hopanos e moretanos aumenta na seqüência $\beta \beta-\beta \alpha-\alpha \beta$, sendo os $\alpha \beta$ mais estáveis em petróleo e rochas geradoras maturas. Segundo Seifert \& Moldowan (1980), uma vez que essa conversão é completada, não resta qualquer componente $17 \beta(\mathrm{H}), 21 \beta(\mathrm{H})$, e a razão dos componentes $17 \beta(\mathrm{H}), 21 \alpha(\mathrm{H})$ para $17 \alpha(\mathrm{H}), 21 \beta(\mathrm{H})$ permanece inalterada para um estágio intermediário de maturidade. Então, em mais altos níveis de maturidade (usualmente na zona de geração de óleo), ocorre uma seleção de isomerizações mais resistente à elevação do grau de maturidade térmica, convertendo os compostos $17 \beta(\mathrm{H}), 21 \alpha(\mathrm{H})$ para as formas $17 \alpha(\mathrm{H}), 21 \beta(\mathrm{H})$. A razão de $\alpha \beta$ hopanos para $\alpha \beta$ hopanos mais $\beta \alpha$ moretanos em $\mathrm{C}_{30}$ pode alcançar valores de até 0,9 a 1 no início da janela de geração de óleo (Seifert \& Moldowan. 1980). Os valores desta razão para as amostras do testemunho RN 16/96 (Tab. 1) e variam de 0,82 a 0,86 , evidenciando um baixo grau de evolução térmica. Costa Neto et al. (1978) invocaram os efeitos de intrusões de diabásio para explicar irregularidades na maturidade quando controlada pelos parâmetros geoquímicos em amostras de folhelhos da Formação Irati. Trigüis (1986) e Mendonça Filho (1994) atentam para o cuidado que deve ser tomado em se tratando da utilização de parâmetros moleculares na estimativa de evolução térmica em sedimentos termalmente afetados por intrusivas ígneas e, principalmente, na possibilidade de ocorrência de hidrocarbonetos migrados nas amostras. Os valores desta razão para amostras do testemunho 5-CA-73-RS-19 são inferiores a 0,8 (Tab. 1).

$\mathrm{O}$ trisnorneohopano (Ts) é mais resistente à degradação termal do que o trisnorhopano (Tm) (Seifert \& Moldowan, 1978). Com isso espera-se que os valores da razão Tm/Ts diminuam com a evolução térmica. Os valores da razão Tm/Ts das amostras dos poços RN 16/96 e 5-CA-73-RS-19 variam de 2,9 a 4,2 e 1,4 a 3,8 , respectivamente (Tab. 1). Estes resultados estão de acordo com os outros parâmetros moleculares descritos, indicando um baixo grau de evolução térmica para essas amostras.

DISCUSSÕES A avaliação do processo de geração de hidrocarbonetos por influência de intrusivas ígneas foi baseada no perfil de evolução térmica. Com a definição dos intervalos de maturação (imaturo, janela de geração de óleo e zona de gás úmido/gás seco) nos dois poços e no afloramento da pedreira SUCAL foi possível fazer comparações e observar o comportamento dos parâmetros geoquímicos ao longo das seções afetadas termicamente pelas intrusivas. As análises de composição orgânica foram importantes para se ter um maior controle na avaliação dos parâmetros geoquímicos (ex.: definição do tipo de querogênio em regiões de alto grau de evolução térmica.

Foi possível observar que não ocorre correlação entre os parâmetros físicos e químicos de maturação. A falta de correlação entre os valores de ICE e Ro (\%) verificada nas amostras do poço RN 16/96 pode estar relacionada com a presença de vitrinitas perídricas, que causariam supressão dos valores de Ro (\%), tendo em vista que o paleoambiente deposicional (extremamente redutor) seria propício para presença deste tipo de vitrinita. Entretanto, Araújo (inédito) verificou que a vitrinita 
presente na camada superior da mina da SIX, embora com um valor muito baixo de reflectância (em torno de $0,29 \%$ ) não apresentou anomalia na intensidade de fluorescência o que seria característico de vitrinitas perídricas. A autora sugere que a vitrinita nesta seção tenha um precursor diferente das vitrinitas húmicas normais e, portanto, não apresentaria um comportamento de maturação similar. Essa não é a única particularidade observada na matéria orgânica da Formação Irati. Wolf \& Corrêa da Silva (1974) constataram a presença de esporinitas com fluorescência vermelho intenso na camada superior da mina da SIX. Segundo Araújo (inédito), essa característica petrográfica incomum ainda é hoje objeto de investigação. Estas observações levam a crer que o ICE seria o indicador de maturação mais confiável a ser aplicado nesta seção sedimentar. Além da complexidade na interpretação dos parâmetros de maturação na Fm. Irati existe a exacerbação deste problema quando o processo de maturação é alterado pela presença das intrusivas.

Os valores de Tmax das amostras do poço $\mathrm{RN}$ 16/96 não apresentam correlação com os parâmetros físicos de maturação na janela de geração de óleo e na zona de geração de gás úmido/gás seco. Estes resultados de Tmax podem estar influenciados pelos altos valores de $\mathrm{S}_{1}$. As razões de isomerização $22 \mathrm{~S} / 22 \mathrm{~S}+22 \mathrm{R}$, $\alpha \beta /(\alpha \beta+\beta \alpha)$ e Tm/Ts das amostras dos poços RN 16/96 e 5-CA-73-RS-19 indicam um grau de evolução térmica moderado (intervalo de maturação entre o início da janela de geração de óleo e o pico de geração), contradizendo a caracterização do grau de evolução térmica obtida pelos parâmetros óticos. Este fato indica a presença de hidrocarbonetos migrados nessas amostras, conforme observado em outros estudos (Trigüis, 1986; Mendonça Filho, 1994).

O poço RN 16/96 apresenta uma intrusiva na profundidade de 47,5 m com 27,2 $\mathrm{m}$ de espessura (Fig. 2). O efeito térmico desta intrusão afetou $19,5 \mathrm{~m}$ da Fm. Irati, dos quais 13,5 m apresentam maturação correspondente à zona de geração de gás úmido/gás seco e 4,5 m estão posicionados na janela de óleo. Foi observado que os teores de COT das amostras situadas dentro da zona de geração de gás úmido/gás seco apresentam grandes variações, sendo possível identificar três situações:

- A primeira situação, característica das amostras situadas próximas à intrusiva, é identificada por possuir teores elevados de COT, baixos valores de $\mathrm{S}_{1}$, $\mathrm{S}_{2}$, IH e altos valores de IP, além da inexistência do extrato orgânico. Essa situação pode ser interpretada como carbono orgânico residual, relacionado ao processo brusco de maturação térmica e à riqueza orgânica original. Os altos valores de IP, para as amostras analisadas, podem ser um reflexo do estágio mais elevado de evolução térmica em que se encontram tais amostras ou ser conseqüência dos valores pouco significativos dos picos $\mathrm{S}_{1}$ e $\mathrm{S}_{2}$.

- A segunda situação é caracterizada por possuir altos valores de IP, baixos valores COT, $\mathrm{IH}, \mathrm{S}_{1}$ e $\mathrm{S}_{2}$, além da inexistência do extrato orgânico (ex.: amostra do poço RN 16/96 coletada na profundidade de 58,1 $\mathrm{m})$. Esses resultados geoquímicos podem estar relacio- nados à conversão e eliminação do carbono orgânico, na forma de hidrocarbonetos líquidos e gasosos, ocorrida sob a influência local de intrusivas ígneas, ou à fácies orgânica. Os altos valores de IP, para as amostras analisadas, já foram explicados anteriormente.

- A terceira situação é caracterizada por possuir valores muito elevados de COT, $\mathrm{S}_{1}, \mathrm{~S}_{2}$, IH e IP, além dos altos valores de extrato orgânico. Esses resultados obtidos nesta seção evidenciam a concentração de hidrocarbonetos migrados, confirmada pelos parâmetros moleculares de maturidade térmica. Araújo et al. (2000) observou inúmeras microfraturas na Fm. Irati que estariam relacionados ao processo de intrusão ígnea. Este fato pode gerar microreservatórios que poderiam acondicionar uma quantidade significativa de óleo migrado, influenciando diretamente os valores de $\mathrm{S}_{1}$.

Dentro do intervalo que apresenta maturação correspondente à janela de geração de óleo no poço RN 16/96 é possível observar o decaimento dos valores de $\mathrm{S}_{1} \mathrm{~S}_{2}$, IH e aumento do IP com o incremento da maturação, mostrando os processos de geração e expulsão dos hidrocarbonetos.

O poço 5-CA-73-RS-19 apresenta uma intrusiva na profundidade de $206,4 \mathrm{~m}$ de 7,5 $\mathrm{m}$ de espessura. Neste poço, o ICE apresenta uma boa correlação com o Ro (\%), sendo todo intervalo analisado caracterizado por possuir uma maturação condizente com a zona de geração de gás úmido. As características geoquímicas observadas neste poço indicam uma situação semelhante à segunda situação que ocorre no poço RN 16/96.

O ICE foi a única técnica utilizada para avaliar o grau de evolução térmica do afloramento da pedreira SUCAL. Neste afloramento ocorre uma intrusiva com $13 \mathrm{~m}$ de espessura que afetou termicamente $6,85 \mathrm{~m}$ da seção analisada. $\mathrm{O}$ intervalo que apresenta maturação compatível com a zona de gás úmido/gás seco possui $1,8 \mathrm{~m}$ e o intervalo com a maturação compatível com a janela de geração de óleo apresenta espessura de 5,5 m.

Através dos resultados de maturação foi possível criar diversas razões de influência térmica para fazer comparações entre os dois poços e o afloramento da pedreira SUCAL. Dos Anjos \& Guimarães (2003) estudaram o afloramento da pedreira SUCAL e constataram que o efeito térmico causado pela intrusiva ígnea modificou a mineralogia preexistente nas rochas da Formação Irati até $6,5 \mathrm{~m}$ de distância da intrusiva. Esta constatação se deve à formação do talco e da calcita, através da reação da dolomita com quartzo $\left(3 \mathrm{CaMg}\left(\mathrm{CO}_{3}\right)_{2}+\right.$ $\left.4 \mathrm{SiO}_{2}+\mathrm{H}_{2} \mathrm{O} \rightarrow \mathrm{Mg}_{3} \mathrm{Si}_{4} \mathrm{O}_{10}(\mathrm{OH})_{2}+3 \mathrm{CaCO}_{3}+3 \mathrm{CO}_{2}\right)$. Segundo Slaughter et al. (1975), esta reação ocorre a temperaturas entre 380 e $440^{\circ} \mathrm{C}$, para uma pressão de 2 Kbar. Devido a esses fatos, é possível interpretar que a influência térmica causada pela intrusiva na encaixante foi superior a $6,5 \mathrm{~m}$.

Com os resultados obtidos nos dois poços e no afloramento, não é possível determinar uma relação direta entre a espessura da intrusiva ígnea e a espessura termicamente afetada, além de não ocorrer uma relação entre a espessura da intrusiva ígnea com a espessura da janela de geração de óleo e a zona de gás úmido/ 
gás seco, pois ocorrem diferenças contrastantes entre as razões de influência térmica do poço RN 16/96 e o afloramento da pedreira SUCAL (Tab. 2).

Vasconcelos et al. (2003) estudaram soleiras que ocorrem intercaladas às rochas da Formação Irati localizadas no estado do Paraná, e concluíram que as intrusões ígneas possuem diferentes litologias (microgabros, basaltos, microdioritos e andesitos). Determinaram, através da análise dos piroxênios, que os cristais foram formados em um intervalo de temperatura que varia predominantemente de 1000 a $1200^{\circ} \mathrm{C}$. Temperaturas abaixo de $1000^{\circ} \mathrm{C}$ são registradas em piroxênios das soleiras de Reserva, chegando a $700^{\circ} \mathrm{C}$, e de Ortigueira, com temperaturas em torno de $750^{\circ} \mathrm{C}$. Já na soleira de Rebouças e na soleira de Irati, foram definidas temperaturas acima de $1200^{\circ} \mathrm{C}$. Estes resultados evidenciam a ocorrência de intrusões de diversas temperaturas, que certamente influenciaram no tamanho da zona termicamente afetada por corpos ígneos.

Dos Anjos \& Guimarães (2003) observaram na pedreira Sucal, nas rochas carbonáticas no contato com a intrusiva ígnea, a ocorrência de sepentina, que diminui com o aumento da distância, dando lugar ao aparecimento do talco. Tendo esses dois minerais uma composição química semelhante, a estabilidade pode estar relacionada com a disponibilidade de sílica no sistema, uma vez que ambos podem ser estáveis a temperaturas inferiores a $800^{\circ} \mathrm{C}$ (Deer et al., 1966). Vasconcelos et al. (2003) observaram a presença de sanidina nas rochas encaixan- tes das soleiras localizados no estado do Paraná, caracterizando a ocorrência da fácies sanidinito que representa temperaturas superiores a $900^{\circ} \mathrm{C}$. Através destas constatações, foi evidenciada a diferença de temperatura das intrusões ocorridas no estado do Paraná e no estado de Goiás, com uma diferença de no mínimo $100^{\circ} \mathrm{C}$.

Com base em suposições razoáveis, que se aproximam de condições naturais, Jaeger (1957) calculou a temperatura em rochas adjacentes a uma intrusão que tem forma tabular infinita de espessura $\mathrm{D}$, isto é, a forma de grandes diques. Como primeira aproximação, intrusões plutônicas alongadas podem ser tratadas como diques verticais. Os cálculos de Jaeger consideram o calor liberado na cristalização do magma e se baseiam no pressuposto de que a transferência de calor induzida pelo fluxo de fluidos pode ser desprezado. Neste mesmo trabalho Jaeger ressaltou a importância da profundidade em que ocorre a intrusão, pois este fator influencia no resfriamento do corpo ígneo, e também fez uma aproximação do período no qual é mantida a temperatura (quase) máxima da rocha regional, que é proporcional ao quadrado da espessura da intrusão.

Corrêa (2007) fez uma simulação numérica do halo térmico da soleira, caracterizado, segundo os dados de modelagem de refletância da vitrinita, por uma faixa acima e abaixo da soleira com espessura equivalente à espessura da soleira encaixada nos estratos geradores da Formação Irati. Entretanto, através dos resultados apresentados neste trabalho foi possível constatar

Tabela 2 - Razões de influência térmica em função da espessura da intrusiva ígnea, além da provável temperatura de intrusão da rocha ígnea.

\begin{tabular}{l|c|c|c}
\cline { 2 - 4 } & \multicolumn{2}{|c}{ RN 16/96 } & \multicolumn{2}{c}{ 5-CA-73-RS-19 } & $\begin{array}{c}\text { Afloramento } \\
\text { SUCAL }\end{array}$ \\
\hline Espessura da intrusiva & $27,2 \mathrm{~m}$ & $7,5 \mathrm{~m}$ & $13 \mathrm{~m}$ \\
\hline Seção afetada & $19,5 \mathrm{~m}$ & $>2,3 \mathrm{~m}$ & $6,85 \mathrm{~m}$ \\
\hline $\begin{array}{l}\text { zona de gás úmido - gás seco } \\
\text { Janela de geração de óleo }\end{array}$ & $13,6 \mathrm{~m}$ & $>2,3 \mathrm{~m}$ & $1,8 \mathrm{~m}$ \\
\hline $\begin{array}{l}\text { Seção afetada/ Espessura } \\
\text { da intrusiva }\end{array}$ & $4,5 \mathrm{~m}$ & $?$ & $5,0 \mathrm{~m}$ \\
\hline $\begin{array}{l}\text { zona de gás úmido-seco/ } \\
\text { Espessura da intrusiva }\end{array}$ & 0,71 & $>0,30$ & 0,53 \\
\hline $\begin{array}{l}\text { Janela de geração de óleo/ } \\
\text { Espessura da intrusiva }\end{array}$ & 0,17 & $>0,30$ & 0,14 \\
\hline $\begin{array}{l}\text { Provável temperatura } \\
\text { de intrusão }\end{array}$ & $\geq 1200^{\circ} \mathrm{C}^{*}$ & $?$ & $\leq 1100^{\circ} \mathrm{C}^{* *}$ \\
\hline
\end{tabular}

* Vasconcelos et al. (2003)

** Dos Anjos \& Guimarães (2003) 
que a influência térmica não depende unicamente da espessura da intrusiva ígnea, mas depende, também, de outros fatores: temperatura de intrusão do corpo ígneo, profundidade em que ocorreu a intrusão e, provavelmente, a condutividade térmica (composição mineralógica, composição orgânica, permeabilidade, porosidade e fluidos presentes) que explicaria as diferenças que ocorreram nos dois poços e no afloramento.

Os fatores que influenciam o tamanho da zona afetada termicamente também agem sob as razões de influência térmica (Tab. 2), por isso ocorreram discrepâncias entre as razões zona de gás úmido-secolespessura da intrusiva e janela de geração de óleolespessura da intrusiva. Essas discrepâncias seriam explicadas devido às diferenças de temperatura de intrusão ígnea e a litologia da encaixante. No afloramento da pedreira SUCAL a razão espessura da janela de óleo por espessura da intrusiva ígnea é mais elevada, devido à ocorrência do predomínio de carbonatos e dolomitos.

Os resultados apresentados neste trabalho evidenciaram a qualidade e a quantidade da matéria orgânica para a geração de petróleo, além da presença de um sistema petrolífero atípico, que, segundo Magoon \& Dow (1994), ocorre quando rochas geradoras são termalmente maturadas por intrusivas ígneas. A Formação Irati apresenta grandes variações de espessura, variando de alguns centímetros a $240 \mathrm{~m}$ (Corrêa \& Pereira, 2005), onde ocorre um grande número de intrusões ígneas referentes ao magmatismo Serra Geral, devido à facilidade proporcionada pela foliação presente nesta formação. Devido a esses fatores e aos resultados apresentados neste trabalho, é possível afirmar que ocorreu a geração de quantidades significativas de petróleo na Bacia do Paraná. Araújo et al. (2000) fizeram uma estimativa da quantidade de hidrocarboneto gerado pelo processo de intrusão ígnea na Bacia do Paraná e chegaram a um valor entre 500 e $3500 \times 10^{3} \mathrm{~m}^{3} \mathrm{HC} / \mathrm{km}^{2}$.

CONCLUSÕES As amostras da Formação Irati apresentam quantidade e qualidade adequadas de matéria orgânica para geração de hidrocarbonetos líquidos e gasosos. O fator condicionante no processo natural de geração foi o efeito térmico, que neste caso, foi fornecido em parte pelas intrusivas ígneas (diques e/ou soleiras).

Foi possível observar que os parâmetros de ma- turação não apresentaram correlação, sendo o ICE a análise mais confiável para avaliar o efeito térmico das intrusivas na Fm. Irati.

No poço RN 16/96 ocorre a zona imatura, a janela de geração de óleo e a zona de gás úmido/gás seco. A variação dos teores de COT do poço RN 16/96 ao longo da zona de gás úmido/gás seco está provavelmente relacionada à presença de microreservatórios de óleo, ocasionados pelo processo de intrusão, à conversão e eliminação de hidrocarbonetos e à ocorrência de carbono orgânico residual. Já as amostras coletadas no poço 5-CA-73-RS-19 apresentam maturação condizente com a zona de gás úmido/gás seco. Os resultados geoquímicos dessas amostras sugerem a ocorrência de conversão e eliminação de hidrocarbonetos nesta seção. No afloramento da pedreira SUCAL foi constatada a ocorrência da zona imatura, da janela de geração de óleo e da zona de gás úmido/gás seco.

A influência térmica sofrida pelas amostras da Formação Irati em contato com corpos ígneos não depende unicamente da espessura da intrusiva ígnea, mas depende, também, de outros fatores; como temperatura de intrusão do corpo ígneo, profundidade em que ocorreu a intrusão e, provavelmente, a condutividade térmica da rocha encaixante, os quais explicariam as diferenças que ocorreram nos resultados das áreas estudadas.

Levando em consideração o tamanho da Bacia do Paraná $\left(1.100 .000 \mathrm{~km}^{2}\right)$, a espessura da Formação Irati, o grande número de intrusões ígneas ocorridas durante o magmatismo Serra Geral e a ocorrência do processo de geração de petróleo por influência térmica de intrusivas ígneas, é possível afirmar que essa associação foi responsável pela geração de quantidades significativas de petróleo nesta bacia.

Agradecimentos Ao PRH-18 da Agência Nacional do Petróleo (ANP), pelo financiamento do trabalho e pela bolsa concedida. A CPRM e a PETROBRAS, pelo fornecimento dos testemunhos (5-CA-73-RS-19 e RN 16/96) para a realização do trabalho. Ao CNPq, pelo financiamento do projeto CNPq/CTPETRO 2001/2002 - Unb/UFRJ intitulado "Estudo da influência térmica das intrusões ígneas no principal horizonte potencialmente gerador da porção setentrional na bacia do Paraná: Formação Irati". À geóloga Carla Viviane Araújo (Petrobras/CENPES).

\section{Referências}

Araújo L.M. 2001. Análise da expressão estratigráfica dos parâmetros de geoquímica orgânica e inorgânica nas seqüencias deposicionais Irati. Tese de Doutoramento, Instituto de Geociências, Universidade Federal do Rio Grande do Sul, 2 v., 307 p.

Araújo L.M., Trigüis J.A., Cerqueira J.R., Freitas C.S. 2000. The atypical Permian petroleum system of the Paraná Basin, Brazil. In: Mello M.R. \& Kats B.J. (eds.) Petroleum system of South Atlantic margins. AAPG Memoir 73:377-402.
Barnard P.C., Collins A.G., Cooper B.S. 1981. Generation of hydrocarbons - time, temperature and source rock quality. In: Brooks J. (eds.) Organic Maturation Studies and Fossil Fuel Exploration. London, Academic Press, $337-$ 342.

Bigarella J.J. 1972. Geologia da Formação Irati. In: Conferências do Simpósio sobre Ciência e Tecnologia do Xisto, Curitiba, Atas, 82p.

Corrêa L.M.S.A. 2007. Avaliação do efeito térmico das soleiras nas rochas geradoras da Formação Irati através 
de técnicas de modelagem numérica. Dissertação de Mestrado. Departamento de Geologia. Universidade Estadual do Rio de Janeiro, 96 p.

Corrêa L.M.S.A. \& Pereira E. 2005. Estudo da distribuição das intrusões mesozóicas e sua relação com os sistemas petrolíferos da Bacia do Paraná. In: Simpósio de Vulcanismo e Ambientes Associados, 3, Cabo Frio, Anais, p. 21-26.

Costa Neto C., Furtado E.G., Concha F.J.M., Cardoso J.N. e Quadros L.P. 1978. Anomalies in the stratigraphic distribution of hydrocarbons in the Irati oil-shale. Chem. Geol., 23:181-192.

Daemon R.F. \& Quadros L.P. 1970. Bioestratigrafia do Neopaleozóico da Bacia do Paraná. In: SBG, Congresso Brasileiro de Geologia, 24, Brasília, DF, Anais, p. 359412.

Deer W.A., Howie R.A., Zussman J. 1966. An introduction to the rock forming minerals. London, Longmans, Green and Co., 559p.

Dos Anjos C.W.D. \& Guimarães E.M. 2003. Evidências de Metamorfismo de Contato nas Rochas da Formação Irati, em Goiás. In: SBGeoq., Congresso Brasileiro de Geoquímica, 9, Belém, PA, Anais, p.587-589.

Jaeger J.C. 1957. The temperature in the neighborhood of a cooling intrusive sheet. American Journal of Science, 255:306-318

Mackenzie A.S. 1984. Applications of Biological Markers in Petroleum Geochemistry. Advances in Petroleum Geochemistry, 1:115-214.

Mackenzie A.S., Patience R.L., Maxwell J.R., Vandenbroucke M., Durand B. 1980. Molecular Parameters of Maturation in the Toarcian Shales, Paris Basin. Geochimica Cosmochimica Acta, 44:1709-1721.

Mackenzie A.S., Brassel S.C., Eglinton G., Maxwell J.R. 1982. Chemical Fossils: The Geological Fate of Steroids. Science, 217:419-503.

Magoon L.B. \& Dow W.G. 1994. The pretroleum system. In: Magoon L.B. \& Dow W.G. (eds.) The pretroleum system - from source to trap. AAPG Menoir, 60:3-24.

Mendes J.C. 1967. The Passa Dois Group. (The Brazilian Portion of the Paraná Basin). In: Bigarella J.J., Becher R.D., Pinto I.D. (eds.) Problems in Brazilian Gondwana Geology. Curitiba, Universidade Federal do Paraná, p. 119-66.

Mendonça Filho J.G. 1994. Estudo Petrográfico e Organogeoquímico de amostras de folhelhos da Formação Irati, Permiano Superor da Bacia do Paraná. Dissertação de Mestrado. Instituto de Geociências, Universidade Federal do Rio Grande do Sul, 248 p.

Milani E.J., Kinoshita E.M., Araújo L.M., Cunha P.R.C. 1990. Bacia do Paraná: Possibilidades Petrolíferas da Calha Central. Boletim de Geociências da Petrobras, Rio de Janeiro, 4(1):21-34.

Milani E.J., França A.B., Schneider R.L. 1994. Bacia do Pa- raná. In: Feijó F.J. (eds.) Estratigrafia das Bacias Sedimentares do Brasil. Rio de Janeiro, Boletim de Geociências da Petrobrás, 8(1):69-82.

Milani E.J. \& Zalán P.V. 1999. An outline of the geology and petroleum systems of the Paleozoic interior basins of South America. Episodes 22:199-205.

Rohrback B.J. 1983. Crude Oil Geochemistry of the Gulf of Suez. In: Bjoroy M. et al. (eds). Advances in Organic Geochemistry, 39-48. Wiley, Chichester.

Santos R.V., Souza P.A., Alvarenga C.J.S., Dantas E.L., Pimentel M.M., Oliveira C.G., Araújo L.M. 2006. Shrimp $\mathrm{U}-\mathrm{Pb}$ zircon dating and palynology of bentonitic layers from the Permian Irati Formation, Paraná Basin, Brazil. Gondwana Research, 9:456-463

Schneider R.L., Muhlmann H., Daemon R.F., Nogueira A.A. 1974. Revisão Estratigráfica da Bacia do Paraná. In: SBG, Congresso Brasileiro de Geologia, 28, Anais, p. 41-65.

Seifert W.M. \& Moldowan J.M. 1978, Application of steranes, terpanes, and non-aromatics to the maturation, migration and source of crude oils. Geochim. Cosmochim. Acta, 42:79-95.

Slaughter J.D., Kerrick D.M., Wall U.J. 1975. Experimental and thermodynamic study of equilibria in the system $\mathrm{CaO}-\mathrm{MgO}-\mathrm{SiO} 2-\mathrm{H} 2 \mathrm{O}-\mathrm{CO} 2$. American Journal of Science, 275:141-162.

Tissot B.P. \& Welte D.H. 1984. Petroleum Formation and Occurrence. 2 ed., Berlin: Springer-Verlag, 699p.

Trigüis J.A. 1986. An Organic Geochemistry Investigation of Heat - Effected Sediments in the Paraná Basin (Brazil). Ph.D. Thesis, NewCastle: Organic Chemistry Unit, Department of Geology, University of NewCastle, $203 p$.

Tyson R.V. 1995. Sedimentary Organic Matter. Organic facies and palynofacies. Londres, Chapman \& Hall., $615 \mathrm{p}$.

Vasconcelos E.M.G., Petersohn E., Barbosa M.A.D., Vanzela G.A., Mancini F., Pinese, J.P.P.; Cândido, A.G. 2003. Estudo Petrográfico e Geoquímico de Soleiras Encaixados nas Rochas Sedimentares da Formação Irati no Estado do PR. In: SBGeoq., Congresso Brasileiro de Geoquímica, 9, Belém (PA), Anais, p. 642-644.

White I.C. 1908. Relatório final da Comissão de Estudos das Minas de Carvão de Pedra do Brasil. Rio de Janeiro, DNPM, Parte I, 300p.

Wolf M. \& Corrêa Da Silva Z.C. 1974. Petrographic Description and Facies Analysis of Some Samples from the Oil Shale of the Irati Formation (Permian). In: SBG, Congresso Brasileiro de Geologia, 28, Porto Alegre, Anais, 1:159-170.

Manuscrito ID BR 25 Submetido em 19 de dezembro de 2007 Aceito em 15 de maio de 2008 